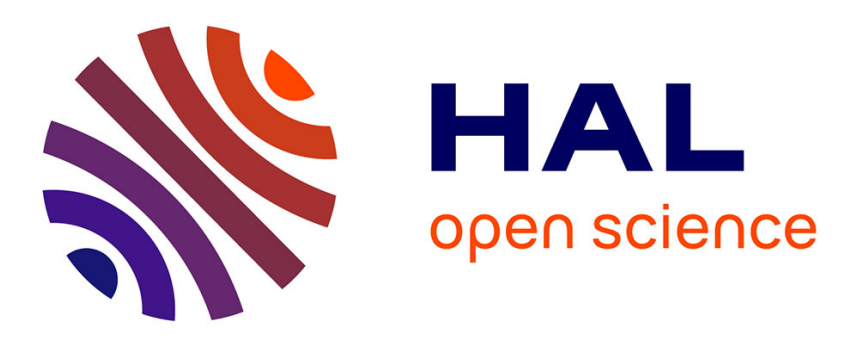

\title{
Intumescent polypropylene: Interactions between physical and chemical expansion
}

Tsilla Bensabath, Johan Sarazin, Maude Jimenez, Fabienne Samyn, Serge Bourbigot

\section{- To cite this version:}

Tsilla Bensabath, Johan Sarazin, Maude Jimenez, Fabienne Samyn, Serge Bourbigot. Intumescent polypropylene: Interactions between physical and chemical expansion. Fire and Materials, 2019, Fire and Materials, 10.1002/fam.2790 . hal-02414122

HAL Id: hal-02414122

https://hal.univ-lille.fr/hal-02414122

Submitted on 16 Dec 2019

HAL is a multi-disciplinary open access archive for the deposit and dissemination of scientific research documents, whether they are published or not. The documents may come from teaching and research institutions in France or abroad, or from public or private research centers.
L'archive ouverte pluridisciplinaire HAL, est destinée au dépôt et à la diffusion de documents scientifiques de niveau recherche, publiés ou non, émanant des établissements d'enseignement et de recherche français ou étrangers, des laboratoires publics ou privés. 


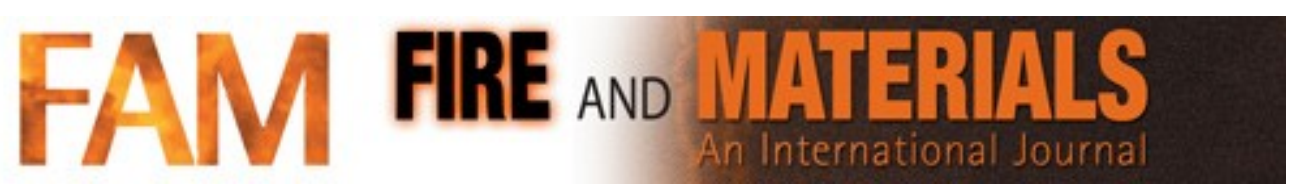

\section{Intumescent polypropylene: Interactions between physical and chemical expansion}

\begin{tabular}{|r|l|}
\hline Journal: & Fire and Materials \\
\hline Manuscript ID & FAM-19-0153.R1 \\
\hline Wiley - Manuscript type: & Interflam 2019: Materials Behaviour in Fire \\
\hline Author: & n/a \\
\hline Complete List of Authors: & $\begin{array}{l}\text { Bensabath, Tsilla; Université de Lille, UMET } \\
\text { Sarazin, Johan; Université de Lille, UMET } \\
\text { Jimenez, Maude; Université de Lille, UMET } \\
\text { Samyn, Fabienne; ENSCL, UMET-ISP } \\
\text { Bourbigot, Serge; ENSCL, UMET; University of Lille, UMET }\end{array}$ \\
\hline Keywords: & $\begin{array}{l}\text { Intumescence, Expandable graphite, Modified ammonium polyphosphate, } \\
\text { Polypropylene, Fire behavior }\end{array}$ \\
\hline &
\end{tabular}

\section{SCHOLARONE Manuscripts}




\title{
INTUMESCENT POLYPROPYLENE: INTERACTIONS BETWEEN PHYSICAL AND CHEMICAL EXPANSION
}

\author{
Tsilla Bensabath*, Johan Sarazin, Maude Jimenez, Fabienne Samyn, Serge Bourbigot \\ Univ. Lille, ENSCL, UMR 8207, UMET, Unité Matériaux et Transformations, F 59000 Lille, France
}

\begin{abstract}
To decrease the reaction to fire of a highly flammable plastic, polypropylene (PP), the concept of intumescence was applied. Two intumescent systems were designed, based on different mechanisms: physical expansion with expandable graphite (EG) and chemical expansion with modified ammonium polyphosphate (AP). Fire behavior of PP containing $\mathrm{EG}$, AP or an AP/EG mixture with a total loading of $10 \mathrm{wt} \%$ was evaluated by cone calorimetry at $35 \mathrm{~kW} \cdot \mathrm{m}^{-2}$. Thermocouples allowed measuring the temperature at the backside or inside samples over time and evaluating the thermal barrier of these intumescent materials. Two grades of AP (difference in composition) and several grades of EG (difference in expansion characteristics) were compared. Mixing AP and EG does not create a synergistic effect in studied conditions. Contrarily, the incorporation of small amount of EG in PP-AP modifies heat transfer in the coating, creating a strong anisotropy. Graphite worms are trapped vertically into the expanded AP, which increases the transverse heat conductivity (lower efficiency of the thermal barrier) and decreases the fire performance. This phenomenon disappears in thicker specimens. While a higher expansion volume of graphite worms improves fire performances of PP with only small amount of EG $(1 \mathrm{wt} \%)$, this effect is not noticeable with $\mathrm{AP} / \mathrm{EG}$ mixtures.
\end{abstract}

\section{KEYWORDS}

Intumescence; Expandable graphite; Modified ammonium polyphosphate; Polypropylene; Fire behavior

\section{INTRODUCTION}

Plastics find more and more applications in many industrial sectors: building, transportation, electrical engineering, paper industry, etc. In particular, polypropylene (PP) is the fastest growing commodity plastic worldwide. However, organic polymer systems are flammable and lead to greater fire risks. The high carbon and hydrogen content of PP makes it combustible. To decrease its reaction to fire, flame-retardants (FRs), acting chemically or physically on the condensed or gaseous phase, can be incorporated in the bulk. ${ }^{1}$

Firstly, halogenated compounds were used as FRs because they interfere with free radicals in gas phase. However, their use is limited because of their oxidizing nature or potential toxicity. Inorganic hydroxide compounds are another kind of FRs. They undergo dehydration reactions under fire conditions. This endothermic dehydration decreases the temperature, the released water dilutes the fuel / oxygen mixture and a ceramic layer is formed in the condensed phase. However, large amounts of FRs are needed, which modify the mechanical properties of the polymer. Finally, intumescent compounds can also be considered as FRs for polymeric systems. ${ }^{2}$ They lead to materials exhibiting high fire 
performance ${ }^{3}$. Indeed, when heated beyond a critical temperature, an intumescent material begins to swell and then to expand. A charred layer is formed at the surface, protecting the underlying material from the action of the heat flux or the flame (thermal barrier) and limiting the transport of decomposition gases and of oxygen from the material and from the flame, respectively. ${ }^{4}$

Intumescence can be obtained from a series of chemical reactions occurring timely or using physical expansion phenomena. In the first case, typically, the combination of three main ingredients makes intumescence possible: an inorganic acid or a material yielding acidic species upon heating (e.g. phosphate), a char former (e.g. pentaerythritol) and a component that decomposes at the right temperature and at the right time to enable the blowing of the system (e.g. melamine). ${ }^{5}$ Modified ammonium polyphosphate (AP) is a well-known example of this kind of FRs. More sophisticated FRs combining the three ingredients in one molecule were designed but they provide similar performance as the conventional formulation ${ }^{6,7}$. The second case (physical expansion) can be obtained by the rapid sublimation of a molecule (and/or the decomposition products) leading to the expansion of the top degraded layer of the polymer to make an intumescent coating. This mechanism occurs when using expandable graphite (EG), which acts both as a carbonization compound and a blowing agent ${ }^{8}$. EG is a synthesized intercalation compound of graphite that expands or exfoliates when heated. A wide variety of chemical species can be used to intercalate graphite materials (e.g. sulfate or nitrate $)^{9}$. EG was incorporated in PP alone ${ }^{10}$ or in combination with conventional intumescent ingredients ${ }^{11-13}$.

This paper examines interactions and possible synergies between these two modes of action of intumescence: physical expansion with EG and chemical expansion with AP. Indeed, synergistic effects between these two components were already demonstrated in different materials, such as polyurethane foams ${ }^{14}$, wood-PP composites ${ }^{15}$, jute-PP composites $^{16}$, poly(butylene terephthalate) ${ }^{17}$, polylactide ${ }^{18}$ or acrylonitrile-butadiene-styrene resin ${ }^{19}$. This work focuses on PP. Reaction to fire of PP containing EG and AP in different ratios (total loading of $10 \mathrm{wt} \% \mathrm{FR}$ ) is evaluated by cone calorimetry and the efficiency of the intumescent barrier is measured quantitatively versus time during the same experiment. Influence of AP grade, sample thickness and graphite expansion volume is investigated. The aim is to better understand the physical and chemical intumescent mechanisms, and particularly to explain a phenomenon observed in a previous work with $9 \mathrm{wt} \% \mathrm{AP} / 1 \mathrm{wt} \% \mathrm{EG}$ in $\mathrm{PP}^{20}$.

\section{MATERIAL AND METHODS}

\section{Materials}

Two polypropylenes were used in this work: PPH 9060 supplied by Total petrochemicals (Belgium) and PP 089 Y1E supplied by Repsol (Spain). Cone calorimetry tests showed that both react to fire in the same way. Subsequently, they will not be differentiated and they will be indifferently named PP.

Several expandable graphites were tested: ES 350 F5 and ES 700 F5 supplied by Graphitwerk Kropfmühl (Germany), Nyagraph FP and Nyagraph KP251 supplied by Nyacol (USA) and FireCarb TEG 315 supplied by Minelco Ltd (Italy). Their expansion characteristics are presented in table 1. 
Two modified ammonium polyphosphates supplied by Clariant (Germany) were also compared: Exolit AP760 and Exolit AP766. They are intrinsic intumescent systems containing phosphorus and nitrogen in different proportions (Table 2) acting in synergy. They are mainly based on ammonium polyphosphate as acid source.

\section{Processing}

PP was blended with flame-retardants in a HAAKE Rheomix OS PTW 16 twin-screw extruder. The extruder is a co-rotating intermeshing twin screw with a barrel length of $400 \mathrm{~mm}$ and screw diameter of $16 \mathrm{~mm}(\mathrm{~L} / \mathrm{D}=25)$ with 10 zones. PP and FRs were incorporated using two gravimetric side feeders into the extruder. Polymer flow rate was fixed to extrude about $500 \mathrm{~g} . \mathrm{h}^{-1}$ with a screw speed of $300 \mathrm{rpm}$. The temperature profile of the extruder from feeder to die was set at $200 / 200 / 200 / 200 / 200 / 170 / 185 / 180 / 200 /$ $200^{\circ} \mathrm{C}$. The total loading of FRs in PP was $10 \mathrm{wt} \%$, with different AP/EG ratios.

\section{Cone Calorimetry}

Measurements were carried out with a Fire Testing Technology (FTT) Mass Loss Calorimeter (MLC), following the procedure defined in ASTM E 906. The equipment is identical to that used in oxygen consumption cone calorimetry (ASTM E-1354-90), except that a thermopile in the chimney is used to obtain heat release rate (HRR) rather than employing the oxygen consumption principle. The samples were $100 \mathrm{~mm} \times 100 \mathrm{~mm}$ plates exposed to the heat flux in horizontal orientation. They were $3 \mathrm{~mm}$ thick, except for the study of the influence of material thickness, for which $6 \mathrm{~mm}$ thick specimens were also used. External heat flux was set to $35 \mathrm{~kW} \cdot \mathrm{m}^{-2}$, corresponding to common heat flux in mild fire scenario $^{21,22}$. HRR, peak of HRR (pHRR) and total heat release (THR) were measured with a reproducibility of $\pm 10 \%$.

In addition, temperature gradient in samples and intumescent structures during a conventional cone experiment was monitored using thermocouples embedded vertically (K-type thermocouple of $0.5 \mathrm{~mm}$ diameter). For the $3 \mathrm{~mm}$ thick samples, only one thermocouple was put on the backside of materials. For the $6 \mathrm{~mm}$ thick samples, additional thermocouples were located at different heights, below and above the surface exposed to heat flux, as presented in figure 1. Studied heights are the surface of the sample, $2 \mathrm{~mm}, 4 \mathrm{~mm}$ and $6 \mathrm{~mm}$ (backside of the material) under the surface and $5 \mathrm{~mm}, 10 \mathrm{~mm}$ and $15 \mathrm{~mm}$ above the surface (in the structure after swelling only). In this experimental set-up, it is necessary to assume that additional conductive effects due to thermocouples are negligible.

Each experiment was replicated three times. Data reported in this paper correspond to the most representative of them: it is the experiment that presents the best fire behavior for neat PP and the worst fire behavior for PP with FRs. Average values are not used to avoid a potential loss of information on curves.

\section{RESULTS AND DISCUSSION}

\section{Selection of the Expandable Graphite}

Intumescence produced by expandable graphites is due to the decomposition into gaseous products of an intercalation compound present in the EG structure. These products blast off the graphite flakes and an entangled network of graphite worms is formed at the 
surface of the material. ${ }^{23}$ Nevertheless, the efficiency of this physical intumescence depends on expansion characteristics of EG, in particular the temperature at which the expansion begins. That is why the fire behavior of polypropylene blended with $10 \mathrm{wt} \% \mathrm{EG}$ was tested with five commercial EGs presenting different expansion temperatures (Table 1).

Figure 2 compares curves of heat release rate as a function of time for the different PP-EG mixtures and table 3 gathers values of peak of HRR, total heat release and time to ignition (TTI) during cone calorimeter experiment (with neat PP as a reference). The lowest pHRR is observed for ES 350 F5, ES 700 F5 and Nyagraph FP (91-92 kW.m-2, 76\% lower than neat PP), whose HRR curves are similar. However, THR of Nyagraph FP (66 MJ.m-2, $13 \%$ lower than neat PP) is higher than that of ES $350 \mathrm{~F} 5$ and ES $700 \mathrm{~F} 5$ (56 and $57 \mathrm{MJ}^{-2}$, $26 \%$ and 25\% lower than neat PP, respectively). FireCarb TEG 315 also reduces HRR and THR compared to neat PP (reduction by $65 \%$ and $9 \%$, respectively), but it is slightly less efficient than the previously cited EGs. Finally, Nyagraph KP251 barely improves the fire behavior of PP.

These results can be related to the temperature of expansion of the graphites. The best fire behavior is obtained for a temperature of expansion of $200-230^{\circ} \mathrm{C}$ (ES $350 \mathrm{~F} 5$ and ES 700 F5). Then, the lower the temperature of expansion, the worse the fire behavior. The optimal expansion temperature is related to the rheology of PP as a function of temperature. It is reasonable to assume that if this temperature is too low, PP is not enough molten and prevents or limits EG expansion.

The presence of EG also accelerates the ignition that occurs earlier than that of neat PP (reduction between $18 \%$ and $52 \%$ of TTI, depending on EG). This is due to the good heat conductivity of graphite worms: although it allows a better dissipation of heat through the material, it enhances the decomposition of $\mathrm{PP}^{24}$.

When used as the only flame retardant compound in PP, ES 350 F5 and ES 700 F5 appear to provide similar fire protection. These are similar EG with a different expansion volume (twice as much for ES $700 \mathrm{~F} 5$ ), but the influence of this expansion volume is not noticeable here. Thereafter, ES 350 F5 was kept to study the interaction of EG with modified ammonium polyphosphate, providing a chemical-based intumescence. Then, the influence of the graphite expansion volume will be studied in more detail, especially in AP/EG mixtures.

\section{Interactions between Modified Ammonium Polyphosphate and Expandable Graphite}

Contrary to EG, whose intumescence is due to physical expansion, the expansion induced by AP is chemical. An intumescent char is formed by a series of chemical reactions during burning. To study interactions between these two kinds of intumescence, experiments were carried out on PP blended with AP/EG mixtures in different ratios: 5/5, 9/1 and 9.5/0.5 (wt $\% / \mathrm{wt} \%$ ) and compared to only AP and only EG (10wt $\%$ in PP). Commercial grades Exolit AP766 as AP and ES 350 F5 as EG are used in this section.

Figure 3 presents HRR curves of intumescent materials. Two successive peaks of HRR $\left(67 \mathrm{~kW} \cdot \mathrm{m}^{-2}\right.$ and $\left.145 \mathrm{~kW} \cdot \mathrm{m}^{-2}\right)$ appear for PP containing $10 \%$ AP, corresponding to a respective decrease of $83 \%$ and $62 \%$ compared to neat PP. The first peak is due to ignition and the second peak corresponds to the degradation of the intumescent char ${ }^{25}$. This curve will be discussed in more details in the next section, in comparison with another AP. The HRR curve for the mixture 5\% AP / 5\% EG is close to that obtained for $10 \% \mathrm{EG}$. The mixture 
9.5\% AP / 0.5\% EG has an intermediate behavior between EG and AP (observation of a second peak). Its maximal peak of HRR appears later than for other materials, except for $10 \%$ AP. The mixture 9\% AP / 1\% EG has an unexpected behavior. Compared to neat PP, this mixture improves the fire behavior (reduction by $65 \%$ of pHRR) but its pHRR is higher than that of PP containing only EG and it appears at shorter times than that of PP containing only AP.

The temperature profiles at the backside of intumescent materials, presented in figure 4, allow quantifying the efficiency of the intumescent barrier and complete the previous observations. Compared to neat PP, whose curve was stopped when the thermocouple is no longer in the matter because of the complete decomposition of PP, the slope of the curve (the rate of the temperature rise) decreases faster with intumescent PPs containing 10\% AP and 10\% EG. For mixtures containing 5\% AP / 5\% EG and 9.5\% AP / $0.5 \% \mathrm{EG}$, the initial temperature rise is a little bit faster than PP but then, it is strongly reduced. By contrast, with PP containing 9\% AP / 1\% EG, the temperature rise is quite high at short time. Then, the temperature decreases and a stabilization occurs at the same level than for other blends.

The nature of intumescent phenomena could explain these observations. Figure 5 presents pictures of char residues obtained after the cone calorimetry experiments for the different samples. Degraded PP-AP presents a cohesive char, with a high expansion and a smooth surface (Figure 5.a), whereas non-cohesive worms of graphite can be observed in the PP-EG char (Figure 5.b). When AP and EG are mixed in the polymer (5\% AP / 5\% EG), visual observations suggest that the network of graphite worms is trapped in the intumescent char formed from AP (Figure 5.c). However, with only 1\% EG, there are not enough worms to form an entangled network. Worms are trapped in vertical position (Figure 5.d). They may then disturb the action of AP and enhance heat conductivity through the material. This could explain the sudden increase in temperature. The sample with 9.5\% AP / 0.5\% EG does not present this particular behavior. Performance of this system is closer to that of PP with $10 \%$ AP. It can be assumed that, from a certain threshold, there is too little graphite to disturb the action of AP and to modify heat conductivity (Figure 5.e).

Interactions between AP and EG in PP are fully commented in a previous paper ${ }^{20}$, but this previous study was carried out with another grade of AP. The following section presents a comparison between the fire performances of the two APs, alone or in combination with EG.

\section{Influence of Modified Ammonium Polyphosphate}

The study of AP and AP/EG mixtures as FRs into PP was first carried out with the commercial grade of modified ammonium polyphosphate Exolit AP760 ${ }^{20}$. Experiments were interrupted because of the discontinuation of the marketing of this AP and Exolit AP766 was then used. AP760 and AP766 do not have the same composition (Table 2) and differences in fire properties can be observed.

Figure 6 presents HRR curves and temperature profiles of PP blended with AP760 and with AP766. The maximal peak of HRR of these two materials is close $\left(139 \mathrm{~kW} \cdot \mathrm{m}^{-2}\right.$ for AP760 and $145 \mathrm{~kW} \cdot \mathrm{m}^{-2}$ for AP766) but it appears at very different times (61 s for AP760 and $788 \mathrm{~s}$ for AP766) and HRR profiles are not similar. For PP with AP760, the first peak is high and is followed by a small peak (around 500 s). For PP containing AP766, there are a first 
small peak followed by a stabilization and, then, an important second peak. As for temperature at the backside of materials, AP766 provides a better thermal barrier than AP760: a gap of more than $100^{\circ} \mathrm{C}$ between the two temperatures is observed from $80 \mathrm{~s}$ of test. Intumescent char of AP766 appears earlier but its structure is weaker than that of AP760. Visual observation indicates the formation of cracks at the surface of the intumescent coating. Therefore, AP766 offers a better fire protection at the beginning of the burning. Then, cracks allow a release of gases trapped between the material and the char, which leads to a resumption of ignition and to the high second peak of HRR. Nevertheless, no influence of this second ignition is noticeable on the temperature at the backside of the sample since the char still protects the material and limits heat transfer.

To see how these differences impact the interactions between AP and EG in PP, figure 7 compares HRR curves and temperature profiles of PP blended with AP/EG mixtures (ratios 5/5 and 9/1) for AP760 and AP766. With 5\% AP / 5\% EG, results are very close. There is no influence of the grade of AP, which suggests that fire performances are more related to EG than to AP for this ratio. This observation is confirmed by the similarity of HRR curves of 5\% AP / 5\% EG and of 10\% EG materials (Figure 3). Regarding 9\% AP / 1\% EG mixtures, the unexpected behavior described in the previous section is noticeable with both APs. pHRR are higher than for other intumescent PPs and there is an important rise of temperature at the TTI. Nevertheless, AP was incorporated in a large amount and its influence on fire performances is obvious: with AP760, pHRR is higher and the temperature remains at its maximum value for a longer time than for AP766. The earlier decrease of temperature for AP766 may be related to the faster swelling of this AP. Indeed, for PP blended with $9 \%$ AP / 1\% EG, graphite worms trapped in vertical position delay the blowing of AP because they prevent the formation of a smooth surface of char. The decrease of temperature only observed with these blends is due to the late expansion of the char ${ }^{20}$.

The composition of AP used as FR has an influence on the fire behavior and on the intumescent barrier of PP. Nevertheless, trends observed when AP is mixed with EG are similar with AP760 and AP766. Therefore, it can be assumed that changing AP does not affect the study of the interactions between chemical intumescence of AP and physical intumescence of EG, which is the aim of this work.

\section{Influence of Material Thickness}

All previous results were obtained during cone calorimetry experiments with material specimens measuring $100 \mathrm{~mm} \times 100 \mathrm{~mm} \times 3 \mathrm{~mm}$. To study the influence of material thickness, a comparison with specimens of $6 \mathrm{~mm}$ thick (considered as thermally thick) instead of $3 \mathrm{~mm}$ (considered as thermally thin) was carried out. To get a better idea of what happens upon burning, a mapping of temperatures in intumescent materials during cone calorimetry experiments was made with several thermocouples (section Material and methods, Figure 1). This section focuses on PP blended with 9\% AP / 1\% EG in order to better understand the intumescent phenomenon in this mixture.

Figure 8 only compares temperature profiles at the backside of $3 \mathrm{~mm}$ thick and $6 \mathrm{~mm}$ thick PP blended with 9\% AP / 1\% EG. Then, figure 9 presents temperature profile as a function of time and as a function of the distance to the surface for $6 \mathrm{~mm}$ thick PP blended with $9 \% \mathrm{AP} / 1 \% \mathrm{EG}$, and in comparison with PP blended with 10\% AP. The entire mapping of temperatures for these two intumescent PPs is represented in figure 10, obtained by extrapolation from thermocouple measurements. Char expansion is also shown in figure 10 
(plain black line). Above it, measured temperatures are not relevant because thermocouples are not in solid structure. That is why temperature profiles at $15 \mathrm{~mm}$ above the surface of the material are not represented in figure 9.

At the backside of $6 \mathrm{~mm}$ thick PP blended with 9\% AP / 1\% EG, the temperature slowly increases and stabilizes around $1000 \mathrm{~s}$ (Figure 8). Despite the small amount of EG mixed with AP and the heat conductivity of worms of graphite, there is no significant rise of temperature at the start of burning. The greater thickness of sample could partially explain the change of temperature profile. Graphite worms conduct heat from the surface into the material but heat can be dispersed through PP in last millimeters. Indeed, the difference between $3 \mathrm{~mm}$ thick and $6 \mathrm{~mm}$ thick samples is already noticeable with neat PP. The increase in temperature appears later with thermally thick material. However, for PP blended with $9 \%$ AP / 1\% EG, temperature profiles at $-2,-4$ and $-6 \mathrm{~mm}$ are very close (Figure 9 and Figure 10). There is also no important increase in temperature around $-3 \mathrm{~mm}$, such as in the case of $3 \mathrm{~mm}$ thick sample. That supports the idea that the thickness of the material affects intumescent phenomena.

In $6 \mathrm{~mm}$ thick PP blended with 9\% AP / 1\% EG, expansion of graphite worms from the bottom of the sample is disturbed by phenomena at the surface. That may lead to different orientations of worms, not only normal to the surface. The different development of expansion may also change reactions in the material around $-3 \mathrm{~mm}$. That is why changes in temperature profile are observed between thermally thin and thermally thick materials. Results for $6 \mathrm{~mm}$ thick sample are more similar to those of PP blended with $10 \%$ AP, with a stabilization at a higher temperature. Nevertheless, these results must be considered cautiously since the presence of thermocouples can have an impact on swelling and heat conductivity.

Mapping offers an overall view of the evolution of temperature over time in the sample and in the intumescent structure. Two phases can be observed: a transient phase during which the temperature under the surface increases and the temperature above the surface strongly fluctuates because of char expansion process (thermocouples are covered by the intumescent structure one by one); a steady state during which the temperature becomes uniform and stabilizes. These two phases are observable in figure 9 and figure 10 for PP with $10 \% \mathrm{AP}$ and with $9 \% \mathrm{AP} / 1 \% \mathrm{EG}$, as well as for other AP/EG ratios (mappings not shown here).

\section{Influence of Graphite Expansion Volume}

In 2001, Xie and Qu studied the influence of graphite expansion volume on fire performances of polyethylene. They found that a higher expansion volume allows reaching best results for LOI and thermal stability but a lower char yield. ${ }^{8}$ This section aims at studying the influence of expansion volume on cone calorimetry and thermal barrier results when EG is used alone or in combination with AP in PP.

ES $700 \mathrm{~F} 5$ is an expandable graphite similar to ES $350 \mathrm{~F} 5$ with a double expansion volume (Table 1). Figure 2 showed that it also provides good fire performances to PP. A more detailed comparison between these two EGs is presented here. Dimensions of samples are $100 \mathrm{~mm} \times 100 \mathrm{~mm} \times 3 \mathrm{~mm}$. Commercial grade Exolit AP766 is used as AP.

Figure 11 compares HRR curves for 1\% EG and 10\% EG in PP between ES 350 F5 
and ES $700 \mathrm{~F} 5$. The curve for the mixture 5\% ES $350 \mathrm{~F} 5 / 5 \% \mathrm{ES} 700 \mathrm{~F} 5$ is also presented. With only $1 \%$ EG in PP, pHRR for ES $700 \mathrm{~F} 5\left(300 \mathrm{~kW} \cdot \mathrm{m}^{-2}, 22 \%\right.$ lower than neat PP) is lower than that of ES $350 \mathrm{~F} 5$ (345 kW.m-2, 10\% lower than neat PP). The higher expansion of graphite allows a better fire behavior of the material. The same cannot be said for $10 \% \mathrm{EG}$ in PP, for which the two HRR curves are superimposed. It can be assumed that the protection is optimal in these proportions (reduction by $76 \%$ of pHRR). Increasing the graphite expansion volume does not improve the protection. Mixing 5\% ES 350 F5 and 5\% ES 700 F5 does not modify HRR curve either.

Figure 12 compares ES 350 F5 and ES 700 F5 when they are mixed with AP in PP. It presents HRR curves and temperature profiles at the backside of the material for mixtures with 5\% AP / 5\% EG and with 9\% AP / 1\% EG. Table 4 gathers values of pHRR and THR for the same materials (with neat PP as a reference). For both ratios, the profiles of HRR are similar for both EGs, but fire behavior is better with ES 350 F5. Its pHRR and its THR are lower, especially for 9\% AP / 1\% EG mixture. With regard to the thermal barrier, for 5\% AP / 5\% EG, this trend is reversed: the rise of temperature is slower for ES $700 \mathrm{~F} 5$ than for ES $350 \mathrm{~F} 5$, even if the stabilization is at the same level. For 9\% AP / 1\% EG mixtures, the large increase in temperature at the beginning of burning appears on both curves. The maximum of temperature is reached sooner with ES 350 F5 but the temperature rapidly decreases while it stabilizes with ES 700 F5.

The worse fire behavior observed with ES 700 F5 may be due to the higher expansion of this EG. With graphite worms maintained by the intumescent structure of AP, the surface of intumescent material is getting closer to the resistance of the cone calorimeter and, therefore, heat flux is greater. However, the faster growth of graphite worms can allow a faster dissipation of heat. That explains the slower rise of temperature for 5\% AP / 5\% EG mixture.

\section{CONCLUSION}

Modified ammonium polyphosphate and expandable graphite act as flame-retardants in polypropylene in two different ways. AP expands by chemical reactions leading to the formation of a cohesive intumescent barrier and decomposition gases are trapped under this barrier. EG physically expands and forms an entanglement network of worms at the surface of PP, which allows the dissipation of heat. When AP and EG are mixed, cone calorimetry experiments show that fire performances of PP are not improved compared to only AP or only EG. No synergistic effect is observed in studied ratios. Contrarily, when EG is added in small amount in a chemical intumescent system (9\% AP / 1\% EG), worms disturb the system, increase transverse heat conductivity and decrease fire performances.

Several EGs were tested. Among them, ES 350 F5 and ES 700 F5 allow the best fire protection. They start to expand at $200^{\circ} \mathrm{C}$ and have an expansion volume of 350 and $700 \mathrm{~cm}^{3} \cdot \mathrm{g}^{-1}$, respectively. A higher expansion volume is useful when there is little EG (1\%) in PP but no influence is observed with bigger amount of EG (10\%). When EG is mixed with AP, ES 350 F5 seems to provide a better fire behavior but a higher graphite expansion brings the intumescent swelling closer to the resistance of the cone calorimeter. Conversely, the faster growth of worms with ES 700 F5 provides a better thermal barrier at the beginning of burning.

Two different APs were compared. Experiments show that AP composition modifies 
the properties of intumescent protection and therefore fire behavior of PP. Nevertheless, adding EG modifies the system for both APs similarly. So, interactions between physical and chemical expansions are not dependent on the grade of AP.

Finally, the establishment of intumescent protection and thermal barrier depends on material thickness. Temperature mappings of samples allow seeing that, with a double thickness, the increase in transverse heat conductivity by graphite worms in $9 \%$ AP / 1\% EG mixtures in PP is not noticeable. Temperature profile at the backside of the material is closer than that of PP with $10 \%$ AP.

\section{ACKNOWLEDGEMENT}

This work has received funding from the European Research Council (ERC) under the European Union's H2020 - the Framework programme for Research and Innovation (20142020) / ERC Grant Agreement n 670747 - ERC 2014 AdG/FireBar-Concept.

\section{REFERENCES}

1. Bourbigot S, Duquesne S. Fire retardant polymers: recent developments and opportunities. J Mater Chem 2007;17(22):2283-2300.

2. Marchal A, Delobel R, Le Bras M, Leroy J-M, Price D. Effect of intumescence on polymer degradation. Polymer Degradation and Stability 1994;44(3):263-272.

3. Alongi J, Han Z, Bourbigot S. Intumescence: Tradition versus novelty. A comprehensive review. Progress in Polymer Science 2015;51:28-73.

4. Bourbigot S, Le Bras M, Duquesne S, Rochery M. Recent advances for intumescent polymers. Macromolecular Materials and Engineering 2004;289(6):499-511.

5. Wladyka-Przybylak M, Kozlowski R. The thermal characteristics of different intumescent coatings. Fire and Materials 1999;23(1):33-43.

6. Fontaine G, Bourbigot S, Duquesne S. Neutralized flame retardant phosphorus agent: Facile synthesis, reaction to fire in PP and synergy with zinc borate. Polymer Degradation and Stability 2008;93(1):68-76.

7. Xu B, Wu X, Ma W, Qian L, Xin F, Qiu Y. Synthesis and characterization of a novel organic-inorganic hybrid char-forming agent and its flame-retardant application in polypropylene composites. Journal of Analytical and Applied Pyrolysis 2018;134:231-242.

8. Xie R, Qu B. Expandable graphite systems for halogen-free flame-retarding of polyolefins.

I. Flammability characterization and synergistic effect. Journal of Applied Polymer Science 2001;80(8):1181-1189.

9. Focke WW, Badenhorst H, Mhike W, Kruger HJ, Lombaard D. Characterization of commercial expandable graphite fire retardants. Thermochimica Acta 2014;584:8-16.

10. Sover A, Marzynkevitsch S, Munack B. Processing conditions of expandable graphite in PP and PA matrix and their performance. Mater Plast 2018;55(4):507-510.

11. Zheng Z, Liu Y, Zhang L, Wang H. Synergistic effect of expandable graphite and intumescent flame retardants on the flame retardancy and thermal stability of polypropylene. J Mater Sci 2016;51(12):5857-5871.

12. Zheng Z, Liu Y, Dai B, Meng C, Guo Z. Fabrication of cellulose-based halogen-free flame retardant and its synergistic effect with expandable graphite in polypropylene. Carbohydrate Polymers 2019;213:257-265.

13. Qi F, Tang M, Wang N, et al. Efficient organic-inorganic intumescent interfacial flame retardants to prepare flame retarded polypropylene with excellent performance. RSC Adv 2017;7(50):31696-31706. 
14. Yao W, Zhang D, Zhang Y, Fu T, Guan D, Dou Y. Synergistic flame retardant effects of expandable graphite and ammonium polyphosphate in water-blow polyurethane foam. Advances in Materials Science and Engineering 2019.

15. Guo C, Zhou L, Lv J. Effects of expandable graphite and modified ammonium polyphosphate on the flame-retardant and mechanical properties of wood flour-polypropylene composites. Polymers and Polymer Composites 2013;21(7):449-456.

16. Guo B, Zhang T, Zhang W, Dou Y. Influence of surface flame-retardant layer containing ammonium polyphosphate and expandable graphite on the performance of jute/polypropylene composites. J Therm Anal Calorim 2019;135(4):2367-2375.

17. Zhang W, Ren J, Wei T, Guo W. Synergistic effect between ammonium polyphosphate and expandable graphite on flame-retarded poly(butylene terephthalate). Mater Res Express 2018;5(2):025310.

18. Zhu H, Zhu Q, Li J, Tao K, Xue L, Yan Q. Synergistic effect between expandable graphite and ammonium polyphosphate on flame retarded polylactide. Polymer Degradation and Stability 2011;96(2):183-189.

19. Ge L-L, Duan H-J, Zhang X-G, Chen C, Tang J-H, Li Z-M. Synergistic effect of ammonium polyphosphate and expandable graphite on flame-retardant properties of acrylonitrile-butadiene-styrene. Journal of Applied Polymer Science 2012;126(4):1337-1343. 20. Bourbigot S, Sarazin J, Bensabath T, Samyn F, Jimenez M. Intumescent polypropylene: Reaction to fire and mechanistic aspects. Fire Safety Journal 2019;105:261-269.

21. Babrauskas V. Ignition sources. In: Ignition Handbook. Fire Science Publishers; 2003; 497-590.

22. Schartel B, Hull T. Development of fire-retarded materials - Interpretation of cone calorimeter data. Fire and Materials 2007;31(5):327-354.

23. Bourbigot S, Sarazin J, Samyn F, Jimenez M. Intumescent ethylene-vinyl acetate copolymer: Reaction to fire and mechanistic aspects. Polymer Degradation and Stability 2019;161:235-244.

24. Asante J, Modiba F, Mwakikunga B. Thermal measurements on polymeric epoxyexpandable graphite material. International Journal of Polymer Science 2016;2016:1-12.

25. Bugajny M, Le Bras M, Noel A, Bourbigot S. Use of thermoplastic polyurethanes as carbonisation agents in intumescent blends. Part 3: Modification of the dynamic properties of polypropylene/thermoplastic polyurethane/ammonium polyphosphate formulations with heat and stress. J Fire Sci 2000;18(2):104-129. 
Table 1. Expansion characteristics of expandable graphites

\begin{tabular}{|c|c|c|c|c|c|}
\cline { 2 - 6 } \multicolumn{1}{c|}{} & ES 350 F5 & ES 700 F5 & $\begin{array}{c}\text { Nyagraph } \\
\text { FP }\end{array}$ & $\begin{array}{c}\text { FireCarb } \\
\text { TEG 315 }\end{array}$ & $\begin{array}{c}\text { Nyagraph } \\
\text { KP251 }\end{array}$ \\
\hline $\begin{array}{c}\text { Expansion } \\
\text { volume }\left(\mathbf{c m}^{3} \cdot \mathbf{g}^{-1}\right)\end{array}$ & 350 & 700 & $\geq 230$ & 220 & $\geq 230$ \\
\hline $\begin{array}{c}\text { Expansion start } \\
\text { temperature }\left({ }^{\circ} \mathbf{C}\right)\end{array}$ & $200-230$ & $200-230$ & $170-190$ & 170 & $135-155$ \\
\hline
\end{tabular}


Table 2. Characteristics of modified ammonium polyphosphates

\begin{tabular}{|c|c|c|}
\cline { 2 - 3 } \multicolumn{1}{c|}{} & AP760 & AP766 \\
\hline Phosphorus (wt\%) & $19.0-21.0$ & $23.0-25.0$ \\
\hline Nitrogen (wt\%) & $\approx 14$ & $14.4-16.4$ \\
\hline Decomposition temperature $\left({ }^{\circ} \mathbf{C}\right)$ & $>250$ & $>275$ \\
\hline
\end{tabular}


Table 3. Peak of heat release rate, total heat release and time to ignition of PP with $10 \mathrm{wt} \%$ of different EGs - Comparison with neat PP

\begin{tabular}{|c|c|c|c|c|c|c|}
\cline { 2 - 7 } \multicolumn{1}{c|}{} & PP & $\begin{array}{c}\text { PP - } \\
\text { ES 350 F5 }\end{array}$ & $\begin{array}{c}\text { PP - } \\
\text { ES 700 F5 }\end{array}$ & $\begin{array}{c}\text { PP - } \\
\text { Nyagraph FP }\end{array}$ & $\begin{array}{c}\text { PP - } \\
\text { TEG 315 }\end{array}$ & $\begin{array}{c}\text { PP - } \\
\text { Nyagraph KP251 }\end{array}$ \\
\hline $\begin{array}{c}\text { pHRR } \\
\text { (kW.m-2 }\end{array}$ & 383 & 91 & 92 & 92 & 134 & 308 \\
\hline $\begin{array}{c}\text { Reduction } \\
\text { of pHRR }\end{array}$ & $76 \%$ & $76 \%$ & $76 \%$ & $65 \%$ & $20 \%$ \\
\hline $\begin{array}{c}\text { THR } \\
\text { (MJ.m }^{-2} \text { ) }\end{array}$ & 76 & 56 & 57 & 66 & 69 & 69 \\
\hline $\begin{array}{c}\text { Reduction } \\
\text { of THR }\end{array}$ & $26 \%$ & $25 \%$ & $13 \%$ & $9 \%$ & $9 \%$ \\
\hline TTI (s) & 66 & 32 & 35 & 44 & 53 & 54 \\
\hline $\begin{array}{c}\text { Reduction } \\
\text { of TTI }\end{array}$ & & $52 \%$ & $47 \%$ & $33 \%$ & $20 \%$ & $18 \%$ \\
\hline
\end{tabular}


Table 4. Peak of heat release rate and total heat release of intumescent PPs (AP766 is used as AP) - Comparison with neat PP

\begin{tabular}{|c|c|c|c|c|c|}
\cline { 2 - 6 } \multicolumn{1}{c|}{} & PP & $\begin{array}{c}\text { PP - 5\% AP / } \\
\mathbf{5 \%} \text { 5S 350 F5 }\end{array}$ & $\begin{array}{c}\text { PP - 5\% AP / } \\
\mathbf{5 \%} \text { 5\% 700 F5 }\end{array}$ & $\begin{array}{c}\text { PP - 9\% AP / } \\
\mathbf{1 \%} \text { ES 350 F5 }\end{array}$ & $\begin{array}{c}\text { PP - 9\% AP / } \\
\mathbf{1 \%} \text { ES 700 F5 }\end{array}$ \\
\hline $\begin{array}{c}\text { pHRR } \\
\text { (kW.m-2 }\end{array}$ & 383 & 98 & 121 & 135 & 172 \\
\hline $\begin{array}{c}\text { Reduction } \\
\text { of pHRR }\end{array}$ & $74 \%$ & $68 \%$ & $65 \%$ & $55 \%$ \\
\hline $\begin{array}{c}\text { THR } \\
\text { (MJ.m- }^{-2} \text { ) }\end{array}$ & 76 & 64 & 77 & 60 & 78 \\
\hline $\begin{array}{c}\text { Reduction } \\
\text { of THR }\end{array}$ & & $16 \%$ & $1 \%$ & $21 \%$ & $3 \%$ \\
\hline
\end{tabular}




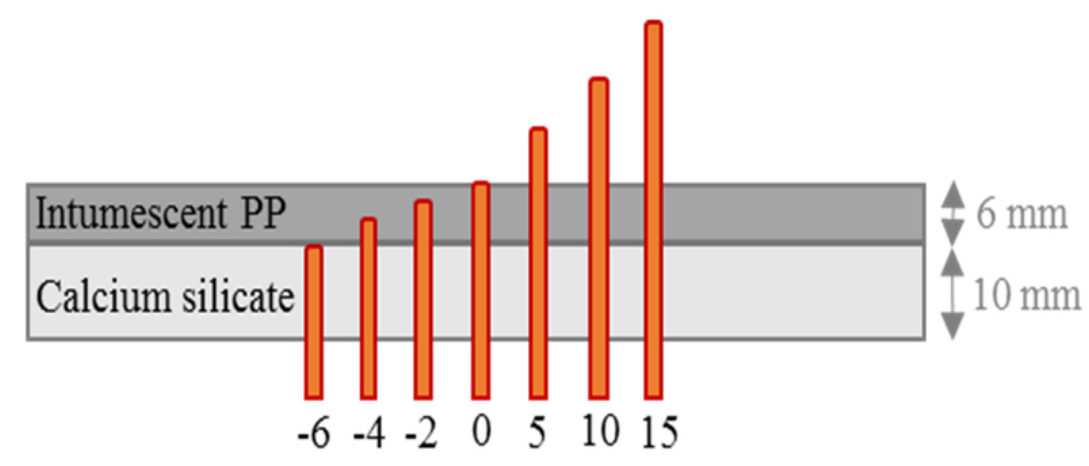

Figure 1. Arrangement of thermocouples (in orange) in $6 \mathrm{~mm}$ thick samples (sectional view) - Numbers are the height in $\mathrm{mm}$ of thermocouples compared to the surface exposed to heat flux $(0 \mathrm{~mm})$

$40 \times 22 \mathrm{~mm}(600 \times 600 \mathrm{DPI})$ 


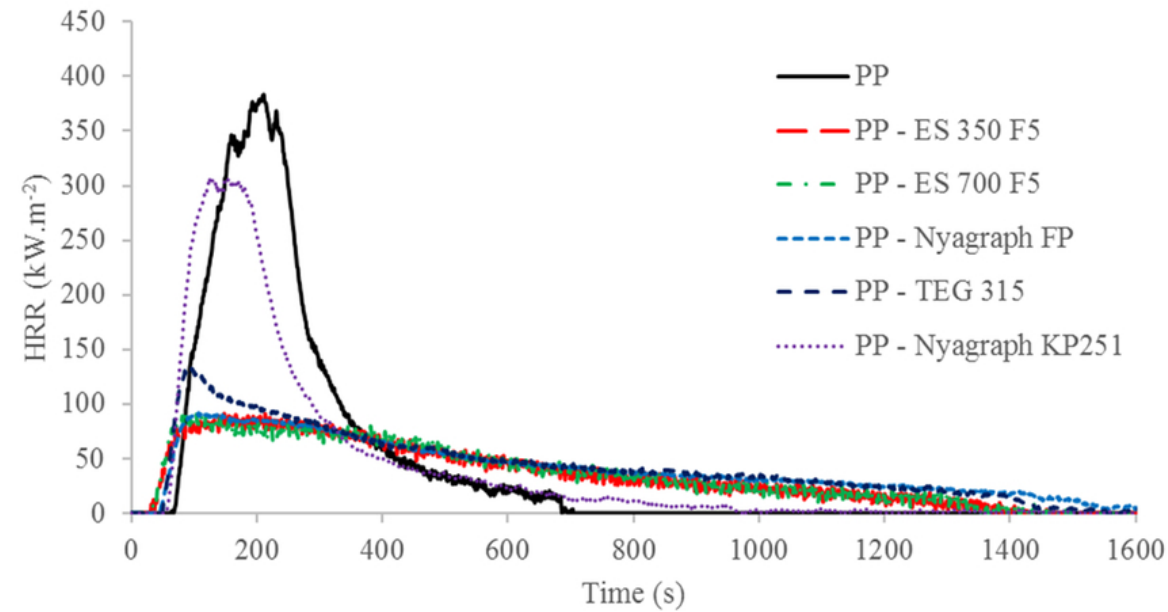

Figure 2. Heat release rate as a function of time of PP with $10 \mathrm{wt} \%$ of different EGs during cone calorimetry experiment (external heat flux $=35 \mathrm{~kW} \cdot \mathrm{m}^{-2}$ )

$40 \times 22 \mathrm{~mm}(600 \times 600 \mathrm{DPI})$ 
Figure 3. Heat release rate as a function of time of intumescent PPs during cone calorimetry experiment (external heat flux $=35 \mathrm{~kW} \cdot \mathrm{m}^{-2}$ ) - AP766 and ES 350 F5 are used as AP and EG, respectively

$40 \times 22 \mathrm{~mm}(600 \times 600 \mathrm{DPI})$ 


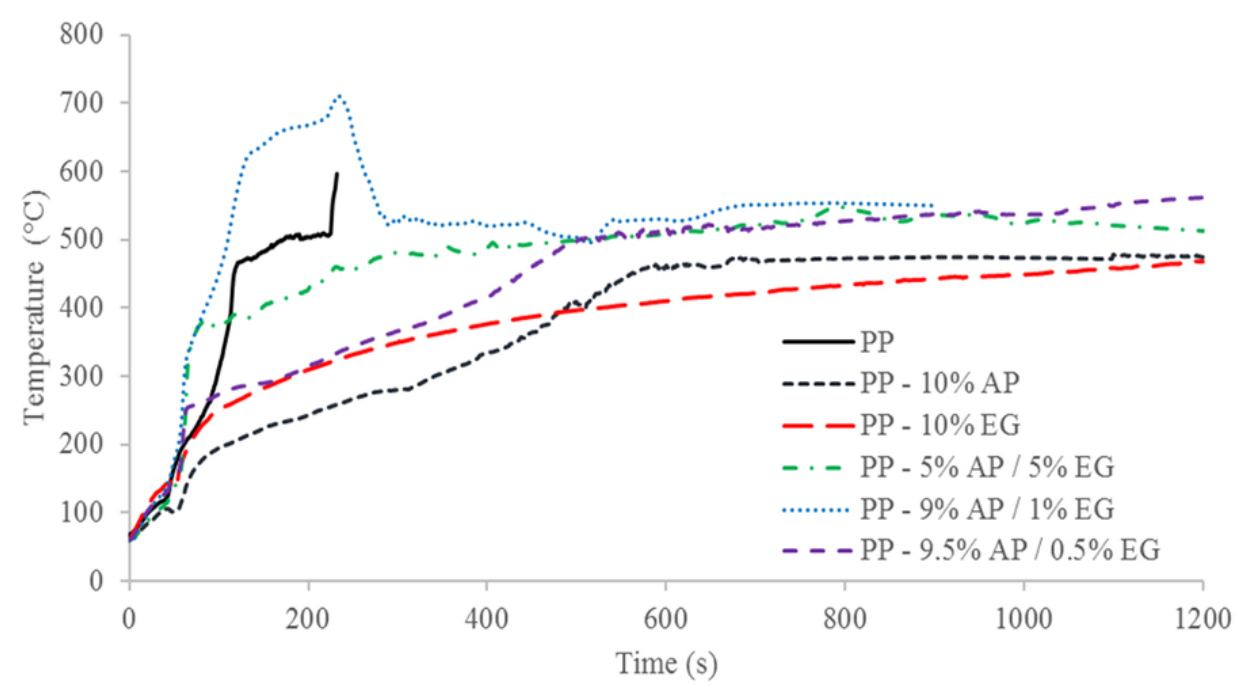

Figure 4. Temperature as a function of time at the backside of intumescent PPs during cone calorimetry experiment (external heat flux $=35 \mathrm{~kW} \cdot \mathrm{m}^{-2}$ ) - AP766 and ES $350 \mathrm{~F} 5$ are used as AP and EG, respectively

$40 \times 22 \mathrm{~mm}(600 \times 600 \mathrm{DPI})$ 

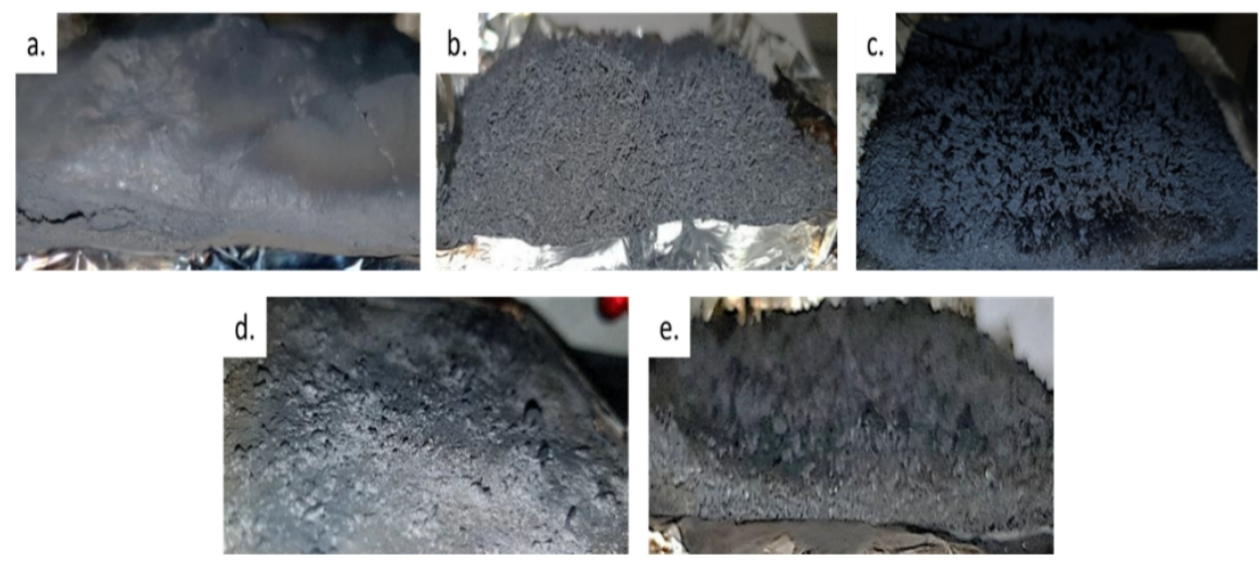

Figure 5. Char residues after cone calorimetry experiment for PP with AP766 / EG 350 F5 at different ratios (wt\% / wt \%): a. $10 / 0$; b. $0 / 10$; c. $5 / 5$; d. $9 / 1$; e. $9.5 / 0.5$

$108 \times 60 \mathrm{~mm}(300 \times 300 \mathrm{DPI})$ 
Figure 6. Heat release rate (left) and temperature at the backside (right) as a function of time of PP with $10 \mathrm{wt} \%$ of different APs during cone calorimetry experiment (external heat flux $=35 \mathrm{~kW} \cdot \mathrm{m}^{-2}$ )

$40 \times 22 \mathrm{~mm}(600 \times 600 \mathrm{DPI})$ 
10
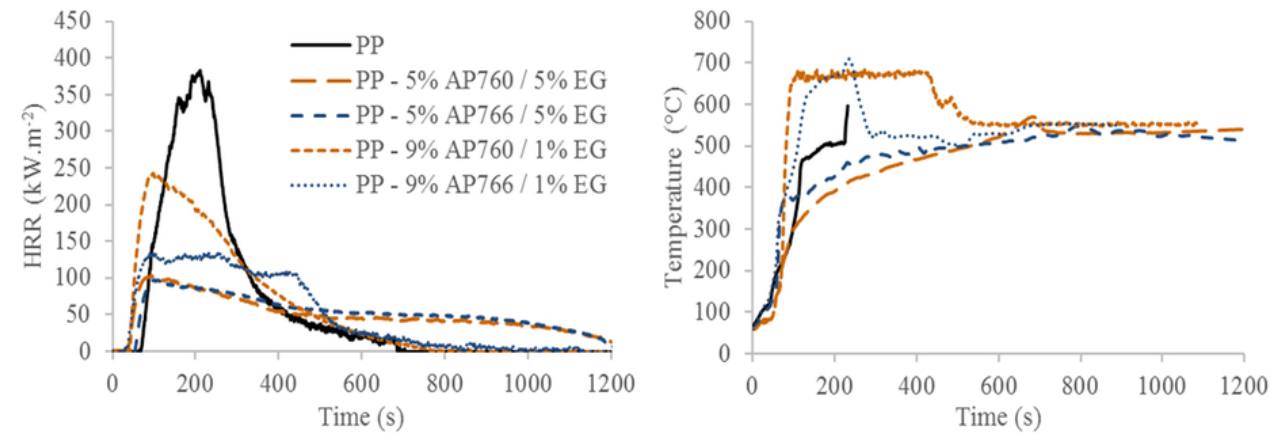

Figure 7. Heat release rate (left) and temperature at the backside (right) as a function of time of intumescent PPs during cone calorimetry experiment (external heat flux $=35 \mathrm{~kW} \cdot \mathrm{m}^{-2}$ ) - ES $350 \mathrm{~F} 5$ is used as EG

$40 \times 22 \mathrm{~mm}(600 \times 600 \mathrm{DPI})$ 
Figure 8. Temperature as a function of time at the backside of materials of different thicknesses during cone calorimetry experiment (external heat flux $=35 \mathrm{~kW} \cdot \mathrm{m}^{-2}$ ) - AP760 and ES $350 \mathrm{~F} 5$ are used as AP and EG, respectively

\section{$40 \times 22 \mathrm{~mm}(600 \times 600 \mathrm{DPI})$}




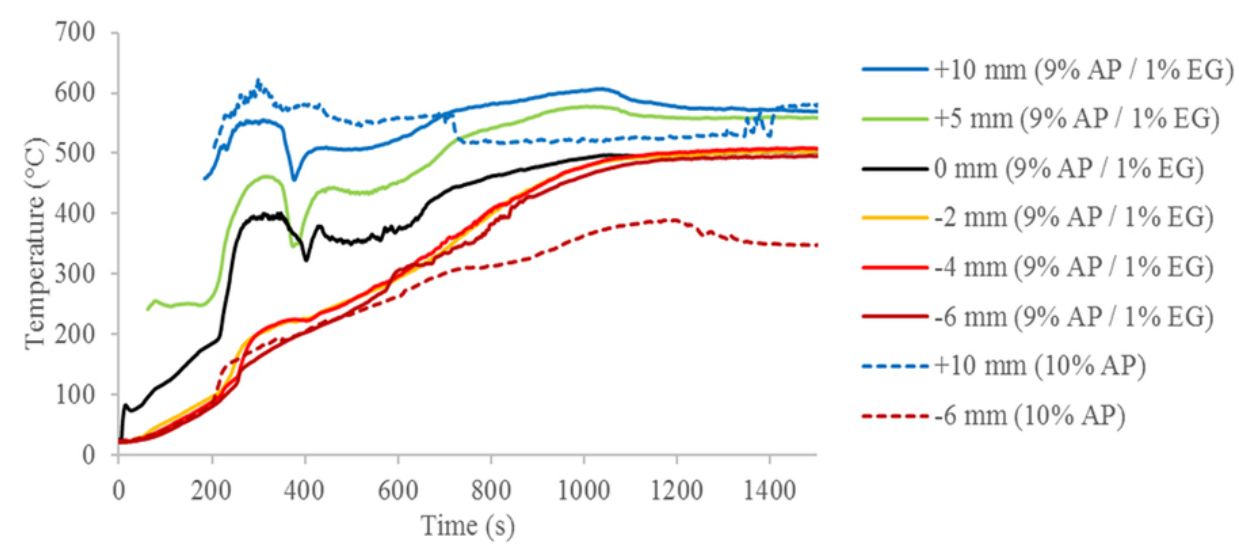

Figure 9. Temperature as a function of time inside and above $6 \mathrm{~mm}$ thick samples of intumescent PPs during cone calorimetry experiment (external heat flux $=35 \mathrm{~kW} \cdot \mathrm{m}^{-2}$ ) $-0 \mathrm{~mm}$ is the height of the surface exposed to heat flux - AP760 and ES 350 F5 are used as AP and EG, respectively

$40 \times 22 \mathrm{~mm}(600 \times 600 \mathrm{DPI})$ 

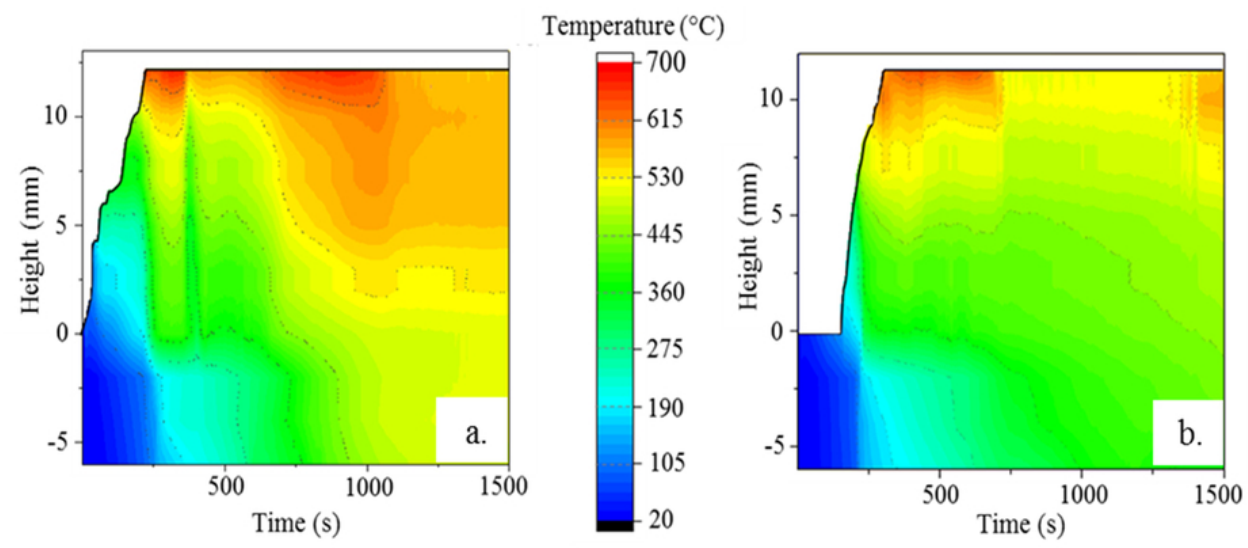

Figure 10. Mapping of temperature inside and above $6 \mathrm{~mm}$ thick samples of PP with AP760 / EG 350 F5 in ratios (wt\% / wt\%): a. 9/1; b. 10/0 during cone calorimetry experiment (external heat flux $=35 \mathrm{~kW} \cdot \mathrm{m}^{-2}$ ) $0 \mathrm{~mm}$ is the height of the surface exposed to heat flux - Plain black line represents char expansion

\section{$40 \times 22 \mathrm{~mm}(600 \times 600 \mathrm{DPI})$}




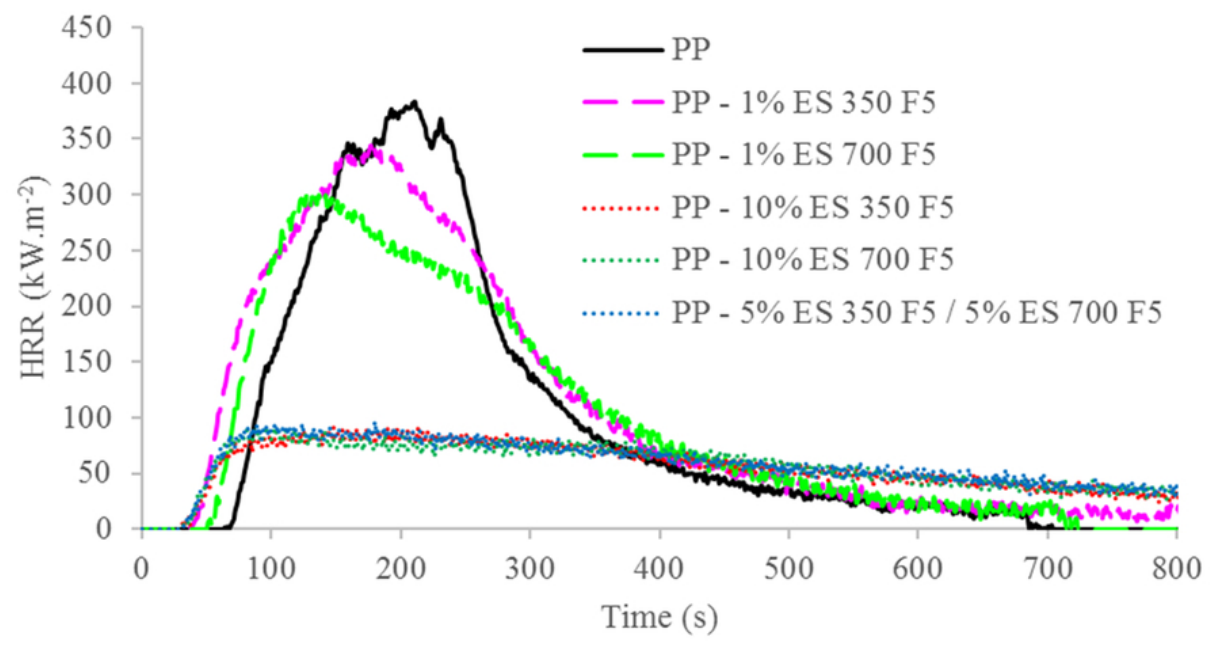

Figure 11. Heat release rate as a function of time of PP with different EGs during cone calorimetry experiment (external heat flux $=35 \mathrm{~kW} \cdot \mathrm{m}^{-2}$ )

$40 \times 22 \mathrm{~mm}(600 \times 600 \mathrm{DPI})$ 

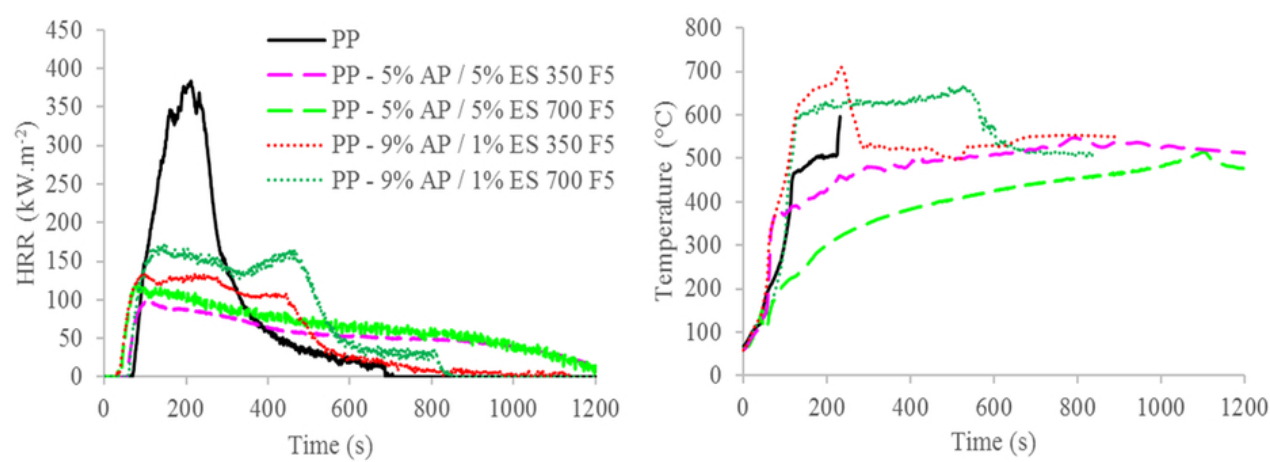

Figure 12. Heat release rate (left) and temperature at the backside (right) as a function of time of intumescent PPs during cone calorimetry experiment (external heat flux $=35 \mathrm{~kW} \cdot \mathrm{m}^{-2}$ ) - AP766 is used as AP

$40 \times 22 \mathrm{~mm}(600 \times 600 \mathrm{DPI})$ 